\title{
Willingness to Receive a COVID-19 Vaccination Among Incarcerated or Detained Persons in Correctional and Detention Facilities - Four States, September-December 2020
}

Marc F. Stern, $\mathrm{MD}^{1}$; Alexandra M. Piasecki, MPH${ }^{2}$; Lara B. Strick, MD ${ }^{1,3}$; Poornima Rajeshwar, MPP4; Erika Tyagi, MS ${ }^{4}$; Sharon Dolovich, JD, PhD ${ }^{4}$; Priti R. Patel, $\mathrm{MD}^{2}$; Rena Fukunaga, $\mathrm{PhD}^{2}$; Nathan W. Furukawa, $\mathrm{MD}^{2}$

Incarcerated and detained persons are at increased risk for acquiring COVID-19. However, little is known about their willingness to receive a COVID-19 vaccination. During September-December 2020, residents in three prisons and 13 jails in four states were surveyed regarding their willingness to receive a COVID-19 vaccination and their reasons for COVID-19 vaccination hesitancy or refusal. Among 5,110 participants, 2,294 (44.9\%) said they would receive a COVID-19 vaccination, 498 (9.8\%) said they would hesitate to receive it, and 2,318 (45.4\%) said they would refuse to receive it. Willingness to receive a COVID-19 vaccination was lowest among Black/African American (Black) (36.7\%; 510 of 1,390$)$ persons, participants aged $18-29$ years $(38.5 \% ; 583$ of 1,516$)$, and those who lived in jails versus prisons $(43.7 \%$; 1,850 of 4,232). Common reasons reported for COVID-19 vaccine hesitancy were waiting for more information (54.8\%) and efficacy or safety concerns (31.0\%). The most common reason for COVID-19 vaccination refusal was distrust of health care, correctional, or government personnel or institutions (20.1\%). Public health interventions to improve vaccine confidence and trust are needed to increase vaccination acceptance by incarcerated or detained persons.

Correctional and detention facilities are at increased risk for COVID-19 outbreaks because of several factors, including difficulty maintaining physical distancing, limited space for isolation or quarantine, poor ventilation, and limited resources for testing and personal protective equipment (1). Members of racial and ethnic minority groups and persons with unstable housing, substance use disorders, and mental illness are disproportionately incarcerated and more likely to have chronic diseases resulting from disparities in social determinants of health (2). The higher prevalence of medical conditions associated with severe COVID-19 illness, delays in timely diagnosis, and inadequate treatment might all contribute to the increased risk for death from COVID-19 among incarcerated or detained persons (3). Recognizing this, some jurisdictions have prioritized incarcerated or detained persons for COVID-19 vaccination.* Data pertaining to willingness

\footnotetext{
* Some jurisdictions have specifically prioritized staff members, residents of correctional or detention facilities, or both in their COVID-19 vaccination plans. https://www.cdc.gov/vaccines/covid-19/covid19-vaccination-guidance.html
}

of residents to be vaccinated while incarcerated or detained are scarce, and routine vaccination coverage is low in these settings (4).

To assess attitudes related to receipt of COVID-19 vaccination, a survey was conducted in three prisons and 10 small-to-medium-sized jails in Washington and one mediumto-large-sized jail each in California, Florida, and Texas, which agreed to participate in an evaluation of willingness of their residents to receive a COVID-19 vaccination. ${ }^{\dagger}$ The survey was conducted during September 22-December 12, 2020, with $96 \%$ of the interviews occurring during November 20 December 12. Interviews were conducted by health care providers, health service administrators, or corrections staff members, depending on the facility and staff member availability. Interviewers attempted to interview all residents within a facility, except those who were in special housing units, quarantine, or medical isolation. Interviews were conducted one-on-one or in small groups in outdoor spaces, communal lounges, or individual cells. Participation was voluntary, and participants could stop the interview at any time. The survey participation rate was $64.2 \%$ (range $=20.0 \%-94.0 \%$ ). $\$$

Interviewers informed participants that correctional and detention facilities were planning for COVID-19 vaccination. Participants were asked "When a vaccine for COVID-19 is approved, will you sign-up to get it?" (willingness). Possible responses were "yes," "no," or "maybe." Participants who answered "no" (refusal) or "maybe" (hesitancy) were then asked to provide a reason for vaccine refusal or hesitancy; responses were open-ended. The primary reason reported for vaccination hesitancy or refusal was coded into one of seven categories: 1) having concerns about efficacy or safety; 2) awaiting more information or to see others vaccinated; 3) distrust of health care, correctional, or governmental personnel or institutions; 4) not perceiving themselves at risk for COVID-19 or perceiving vaccination as unnecessary; 5) being against vaccination in general; 6) believing in a virus- or vaccine-related conspiracy to harm incarcerated or detained persons; or 7) other reasons.

\footnotetext{
$\dagger$ Prisons usually hold persons with sentences $>1$ year and jails hold persons pretrial or with sentences $\leq 1$ year.

$\$ 45$ C.F.R. part 46, 21 C.F.R. part 56; 42 U.S.C. Sect. 241(d); 5 U.S.C. Sect. 552a; 44 U.S.C. Sect. 3501 et seq.
} 
Willingness to receive a COVID-19 vaccination was compared by incarcerated or detained persons' sex, age, and race/ ethnicity and facility type and location. Categories of reasons for vaccine refusal or hesitancy were compared by willingness to receive a vaccination. Multivariable logistic regression was used to compare willingness to receive a vaccination ("yes") and vaccine hesitancy or refusal ("maybe"/"no") by demographic characteristics, facility type, and location. Analyses were conducted using SAS (version 9.4; SAS Institute) and $\mathrm{R}$ software (version 4.0.3; the R Foundation). The University of Washington Institutional Review Board determined that this was an evaluation to inform educational needs and not human subjects research. This activity was reviewed by CDC and was conducted consistent with applicable federal law and CDC policy. 9

\footnotetext{
The denominator for the response rate was resident census of each facility, which included persons in restricted areas who were not approached for interview. Because not all facility residents were approached, the response rate was at least $64.2 \%$ (5,110 participants among a cumulative census of 7,955).
}

Among 5,110 total participants, a total of 2,294 (44.9\%) responded that they would receive, $498(9.7 \%)$ that they would hesitate to receive, and 2,318 (45.4\%) that they would refuse a COVID-19 vaccination (Table 1). Willingness to receive a vaccination was similar among men $(45.0 \%)$ and women (44.4\%), but a higher percentage of women than men indicated they would hesitate to receive a COVID-19 vaccination ( $14.9 \%$ versus $8.7 \%$; $p<0.001$ for "yes" versus "maybe" by sex). Willingness to receive a COVID-19 vaccination increased with age from $38.5 \%$ among participants aged $18-29$ years to $61.8 \%$ among those aged $60-83$ years $(\mathrm{p}<0.001)$. Willingness to receive a vaccination was lowest among Black participants (36.7\%) and highest among Hispanic/Latino (Hispanic) (52.5\%) and American Indian/Alaska Native (48.4\%) participants ( $\mathrm{p}<0.001$ for group). Willingness to receive a COVID-19 vaccination was higher among participants in prisons than among those in jails (50.6\% versus $43.7 \%$; $\mathrm{p}<0.001)$. Lower willingness to receive a vaccination persisted in multivariable analyses among participants who were younger, were Black,

TABLE 1. Willingness to receive a COVID-19 vaccination among incarcerated or detained persons, by demographics and facility — four states, September-December 2020

\begin{tabular}{|c|c|c|c|c|c|c|}
\hline \multirow{2}{*}{$\begin{array}{l}\text { Characteristic (no. with } \\
\text { available information) }\end{array}$} & \multicolumn{4}{|c|}{$\begin{array}{l}\text { Willingness to receive a COVID-19 vaccination } \\
\text { when it is authorized, no. of persons (\%) }\end{array}$} & \multicolumn{2}{|c|}{ Willingness to be vaccinated, ${ }^{*}$ odds ratio $(95 \% \mathrm{Cl})$} \\
\hline & All persons & Yes & Maybe & No & Unadjusted $^{\dagger}$ & Adjusted $^{\S}$ \\
\hline $\begin{array}{l}\text { Total no. of persons } \\
\text { Sex }^{\text {I }}(5,107)\end{array}$ & $5,110(100)$ & $2,294(44.9)$ & $498(9.7)$ & $2,318(45.4)$ & - & - \\
\hline Men & $4,209(82.4)$ & $1,895(45.0)$ & $364(8.7)$ & $1,950(46.3)$ & Referent & Referent \\
\hline Women & $898(17.6)$ & $399(44.4)$ & $134(14.9)$ & $365(40.7)$ & $0.98(0.85-1.13)$ & $1.04(0.86-1.24)$ \\
\hline \multicolumn{7}{|l|}{ Age group, yrs" $(5,070)$} \\
\hline $18-29$ & $1,516(29.9)$ & $583(38.5)$ & $136(9.0)$ & $797(52.6)$ & Referent & Referent \\
\hline $30-39$ & $1,589(31.3)$ & $653(41.1)$ & $181(11.4)$ & $755(47.5)$ & $1.12(0.97-1.29)$ & $1.09(0.94-1.26)$ \\
\hline $40-49$ & $1,011(19.9)$ & $496(49.1)$ & $111(11.0)$ & $404(40.0)$ & $1.54(1.31-1.81)$ & $1.46(1.24-1.73)$ \\
\hline $50-59$ & $661(13.0)$ & $367(55.5)$ & $51(7.7)$ & $243(36.8)$ & $2.00(1.66-2.40)$ & $1.92(1.58-2.32)$ \\
\hline $60-83$ & $293(5.8)$ & $181(61.8)$ & $18(6.1)$ & $94(32.1)$ & 2.59 (1.99-3.35) & $2.62(2.01-3.43)$ \\
\hline \multicolumn{7}{|l|}{ Race/Ethnicity ${ }^{\Uparrow}(4,979)$} \\
\hline White & 2,085 (41.9) & 915 (43.9) & $251(12.0)$ & $919(44.1)$ & Referent & Referent \\
\hline Black/African American & $1,390(28.0)$ & $510(36.7)$ & 105 (7.6) & $775(55.8)$ & $0.74(0.65-0.85)$ & $0.74(0.63-0.86)$ \\
\hline Hispanic/Latino & $1,013(20.4)$ & $532(52.5)$ & $75(7.4)$ & $406(40.1)$ & $1.41(1.22-1.64)$ & $1.34(1.14-1.58)$ \\
\hline $\begin{array}{l}\text { American Indian/ } \\
\text { Alaska Native }\end{array}$ & $221(4.4)$ & $107(48.4)$ & $19(8.6)$ & $95(43.0)$ & $1.20(0.91-1.58)$ & $1.36(1.02-1.80)$ \\
\hline Other & $270(5.4)$ & $128(47.4)$ & $43(15.9)$ & $99(36.7)$ & $1.15(0.89-1.49)$ & $0.93(0.71-1.21)$ \\
\hline \multicolumn{7}{|l|}{ Facility type $\bigcap_{1 * * *}(5,110)$} \\
\hline Jail & $4,232(82.8)$ & $1,850(43.7)$ & $345(8.2)$ & 2,037 (48.1) & Referent & Referent \\
\hline Prison & $878(17.2)$ & $444(50.6)$ & $153(17.4)$ & $281(32.0)$ & $1.32(1.14-1.52)$ & $1.23(1.01-1.51)$ \\
\hline \multicolumn{7}{|l|}{ Facility location" $(5,110)$} \\
\hline Washington & $2,514(49.2)$ & $1,081(43.0)$ & 349 (13.9) & $1,084(43.1)$ & Referent & Referent \\
\hline Florida & $2,015(39.4)$ & $856(42.5)$ & $67(3.3)$ & $1,092(54.2)$ & $0.98(0.87-1.10)$ & $1.17(0.99-1.36)$ \\
\hline California & $449(8.8)$ & $297(66.2)$ & $35(7.8)$ & $117(26.1)$ & $2.59(2.10-3.20)$ & $2.96(2.35-3.72)$ \\
\hline Texas & $132(2.6)$ & $60(45.5)$ & $47(35.6)$ & 25 (18.9) & $1.11(0.78-1.57)$ & $1.41(0.98-2.04)$ \\
\hline
\end{tabular}

Abbreviation: $\mathrm{Cl}=$ confidence interval.

* Bivariate and multivariable regression compared willingness to receive a vaccination ("yes") and vaccine hesitancy or refusal ("maybe"/"no").

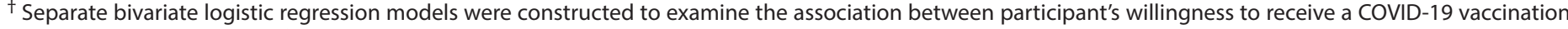
by sex, age, race/ethnicity, facility type, and location.

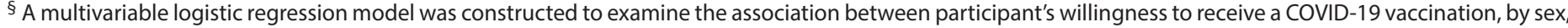
age, race/ethnicity, facility type, and location, adjusting for all characteristics listed in the table.

" $\mathrm{p}<0.001$ comparing "yes," "maybe," and "no" vaccination willingness and characteristic (by chi-square test).

** Prisons usually hold persons with sentences $>1$ year and jails hold persons pretrial or with sentences $\leq 1$ year. 
lived in jails, and were not in California. When stratified by sex and race/ethnicity, willingness to receive a vaccination was highest among Hispanic men (54.9\%) and lowest among Hispanic women (35.8\%) and Black men (36.0\%) (Table 2).

Among 2,816 participants who indicated they would hesitate to receive or would refuse a COVID-19 vaccination, 2,281 $(81.0 \%)$ provided a primary reason. Among 458 participants who would hesitate to receive a COVID-19 vaccination, $251(54.8 \%)$ said they were awaiting more information or to see others vaccinated, and $142(31.0 \%)$ had concerns about efficacy or safety (Table 3). Among 1,823 participants who would refuse a COVID-19 vaccination, $366(20.1 \%)$ cited distrust of health care, correctional, or governmental personnel or institutions; $358(19.6 \%)$ had concerns about efficacy or safety; and $344(18.9 \%)$ did not perceive themselves to be at risk for COVID-19 or thought vaccination was unnecessary.

\section{Discussion}

Among incarcerated or detained persons, willingness to receive a COVID-19 vaccination was lower in this analysis compared with findings from national surveys of the general population over the same period ( $45 \%$ versus $56 \%-67 \%$ ) $(5,6)$. This survey identified significantly lower prevalences of willingness to receive a vaccination among persons who were younger or Black, consistent with similar surveys in the general population. Lower willingness to receive a COVID-19 vaccination among Black participants is not unexpected given historical mistreatment and higher rates of distrust of health care, correctional, and governmental institutions** (7). This

\footnotetext{
** Long-standing systemic health and social inequities have put many persons from racial and ethnic minority groups at increased risk for becoming ill and dying from COVID-19. Inequities in the social determinants of health have historically prevented these groups from having the same opportunities for economic, physical, and emotional health. These inequities are highlighted by the factors that contribute to increased risk for COVID-19 exposure, severe illness from COVID-19, death, and unintended consequences of COVID-19 mitigation strategies. https://www.cdc.gov/coronavirus/2019-ncov/ community/health-equity/racial-ethnic-disparities/index.html
}

finding is particularly concerning because this group is at higher risk for severe illness and death from COVID-19 and overrepresented in the criminal justice system (8).

More than three fourths of participants who reported they were hesitant to receive a COVID-19 vaccination indicated that they had concerns about efficacy or safety or were waiting to see others vaccinated. This finding highlights the need for access to COVID-19 vaccination information that is culturally relevant and appropriate for persons of all health literacy levels, and that is conveyed via multiple formats and languages

TABLE 3. Primary reasons for COVID-19 vaccination hesitancy or refusal among incarcerated or detained persons, by vaccination willingness - four states, ${ }^{*}$ September-December 2020

\begin{tabular}{|c|c|c|c|}
\hline \multirow[b]{2}{*}{$\begin{array}{l}\text { Primary reason for } \\
\text { refusal or hesitancy }\end{array}$} & \multicolumn{3}{|c|}{$\begin{array}{l}\text { Willingness to receive a COVID-19 vaccination } \\
\text { when it is authorized, }, \S \text { no. of persons }(\%)\end{array}$} \\
\hline & $\begin{array}{c}\text { All } \\
\text { respondents } \\
(\mathrm{N}=2,281)\end{array}$ & $\begin{array}{l}\text { Maybe } \\
\text { (hesitancy) } \\
(\mathrm{n}=458)\end{array}$ & $\begin{array}{c}\text { No } \\
\text { (refusal) } \\
(n=1,823)\end{array}$ \\
\hline Efficacy or safety concerns & $500(21.9)$ & $142(31.0)$ & $358(19.6)$ \\
\hline $\begin{array}{l}\text { Awaiting more information } \\
\text { or to see others } \\
\text { vaccinated }\end{array}$ & $493(21.6)$ & $251(54.8)$ & $242(13.3)$ \\
\hline $\begin{array}{l}\text { Distrust of health care, } \\
\text { correctional, or } \\
\text { governmental personnel } \\
\text { or institutions }\end{array}$ & $379(16.6)$ & $13(2.8)$ & $366(20.1)$ \\
\hline $\begin{array}{l}\text { Not perceiving themselves } \\
\text { at risk for COVID-19 or } \\
\text { perceiving vaccination as } \\
\text { unnecessary }\end{array}$ & $353(15.5)$ & $9(2.0)$ & $344(18.9)$ \\
\hline $\begin{array}{l}\text { Against vaccination in } \\
\text { general }\end{array}$ & $253(11.1)$ & $5(1.1)$ & $248(13.6)$ \\
\hline $\begin{array}{l}\text { Believing in a virus- or } \\
\text { vaccine-related } \\
\text { conspiracy to harm } \\
\text { incarcerated or detained } \\
\text { persons }\end{array}$ & $104(4.6)$ & $4(0.9)$ & $100(5.5)$ \\
\hline Other & $199(8.7)$ & $34(7.4)$ & $165(9.1)$ \\
\hline
\end{tabular}

TABLE 2. Willingness to receive a COVID-19 vaccination among incarcerated or detained persons, by sex and race/ethnicity - four states, ${ }^{*}$ September-December 2020

\begin{tabular}{|c|c|c|c|c|c|c|c|}
\hline \multirow[b]{3}{*}{ Race/Ethnicity } & \multirow[b]{3}{*}{ All persons } & \multicolumn{6}{|c|}{ Willingness to receive a COVID-19 vaccination when it is authorized, no. of persons (\%) } \\
\hline & & \multicolumn{3}{|c|}{$\operatorname{Men}^{\dagger}(n=4,081)$} & \multicolumn{3}{|c|}{ Women ${ }^{\S}(n=894)$} \\
\hline & & Yes & Maybe & No & Yes & Maybe & No \\
\hline Total & $4,975(100)$ & $1,795(44.0)$ & $359(8.8)$ & $1,927(47.2)$ & $396(44.3)$ & $134(15.0)$ & $364(40.7)$ \\
\hline White & $2,084(41.9)$ & $687(43.4)$ & $172(10.1)$ & $724(45.7)$ & $227(45.3)$ & 79 (15.8) & 195 (38.9) \\
\hline Black/African American & $1,390(27.9)$ & $453(36.0)$ & $89(7.1)$ & $717(57.0)$ & $57(43.5)$ & $16(12.2)$ & $58(44.3)$ \\
\hline Hispanic/Latino & $1,011(20.3)$ & 489 (54.9) & $54(6.1)$ & $348(39.1)$ & $43(35.8)$ & $21(17.5)$ & $56(46.7)$ \\
\hline American Indian/Alaska Native & $221(4.4)$ & $64(46.0)$ & $11(7.9)$ & $64(46.0)$ & $43(52.4)$ & $8(9.8)$ & $31(37.8)$ \\
\hline Other & $269(5.4)$ & $102(48.1)$ & $33(15.8)$ & $74(35.4)$ & $26(43.3)$ & $10(16.7)$ & $24(40.0)$ \\
\hline
\end{tabular}

* California, Florida, Texas, and Washington.

† $p<0.001$ comparing "yes," "maybe," and "no" vaccination willingness and race/ethnicity among men (by chi-square test).

$\S \mathrm{p}<0.001$ comparing "yes," "maybe," and "no" vaccination willingness and race/ethnicity among women (by chi-square test). 
including video messages, handouts, posters, presentations, peer interactions, and discussions with experts. In addition, opportunities to observe peers, family members, and trusted influencers having positive vaccination experiences could increase vaccine confidence. Nearly one in five participants who would refuse vaccination did not perceive themselves to be at risk for COVID-19 and thought vaccination was unnecessary. Interventions to increase COVID-19 risk perception and highlight the facility and community protective benefits of vaccination might further increase vaccination acceptance. Participants who would refuse vaccination distrusted service providers or the government (20\%), were against vaccination in general (14\%), or believed a COVID-19 vaccination was a conspiracy to harm them $(6 \%)$. These reasons were much more prevalent among incarcerated or detained persons than the prevalence that has been reported among the general population ( 7 ), suggesting that overcoming systemic distrust will be necessary to increase willingness to receive a vaccination among a segment of this population. Interventions to improve vaccine confidence should not be punitive or overly generous to avoid being perceived as coercive, which might worsen trust.

The findings in this report are subject to at least three limitations. First, the correctional and detention facilities were selected based on voluntary participation and are likely not representative of facilities or their residents nationwide. Second, the survey was largely conducted before Emergency Use Authorization of the first COVID-19 vaccine on December 11, 2020; willingness to be vaccinated might have changed given the rapid evolution of the pandemic and vaccine rollout. Finally, stated willingness to receive a COVID-19 vaccination is an imperfect measure of whether a person will accept a vaccination when it is actually offered (9). Persons might be influenced by a variety of peer, environmental, and situational factors that support or hinder receipt of vaccination.

This report underscores the urgent need for interventions that are culturally relevant and appropriate for various health literacy levels to increase vaccine confidence among incarcerated or detained persons. Incarcerated or detained persons might have inherent higher distrust of governmental systems based on their interactions with law enforcement or the justice system or their experiences with institutional racism, emphasizing the need for trusted messengers to directly appeal to these persons. Low vaccine confidence contributes to low vaccination coverage and risks further exacerbating preexisting inequities in COVID-19 outcomes by incarceration or detention status, age, and race/ethnicity. In addition, correctional or detention facilities staff members and residents frequently cycle between the facility and the community. COVID-19 outbreaks in these settings can contribute to community transmission, which intensifies the importance of preventing

\section{Summary}

What is already known about this topic?

Persons living in correctional or detention facilities are at increased risk for COVID-19. Certain jurisdictions have prioritized COVID-19 vaccination of incarcerated or detained persons.

What is added by this report?

Among incarcerated or detained participants at correctional and detention facilities in four states who were surveyed before authorization of COVID-19 vaccines for emergency use, $45 \%$ were willing to be vaccinated. Willingness to be vaccinated was lower among participants who were younger, identified as Black/African American, and lived in jails.

What are the implications for public health practice? COVID-19 outbreaks among incarcerated or detained persons can exacerbate inequities in COVID-19 outcomes and contribute to community transmission. Interventions are needed to improve vaccine confidence among incarcerated or detained persons.

outbreaks in this setting with vaccination (10). It is critically important for public health and criminal justice professionals to promote health equity by addressing vaccine hesitancy and improving vaccine confidence and acceptance among this disproportionately affected population.

\section{Acknowledgments}

The participants in this survey; Amy Parker Fiebelkorn, Samuel Graitcer, Shanaika Grandoit, Erin Kennedy, Carla Lee, Mark Weng, Samantha Williams, CDC COVID-19 Response Team; McLeod Hutchin, Clallam County Jail, Washington; John Johnson, Safani Summons, Pablo Valdes, Anthony Yeber, Miami-Dade Corrections and Rehabilitation Department, Florida; Marco Batres, Joanne Lin, Orange County Jail, California; John Greer, Norma Smith, Cedar Creek Correctional Center, Washington; William Swain, Corrections Center for Women, Washington; Joyce McCoy, Lewis County Jail, Washington; Shane Schoeneberg, Mason County Jail, Washington; Tanner Burns, Mike Hayden, Shannon Matthews, Melody Molinaro, Ian O’Neil, Leann Anderson, Jesus Ordaz, John Slothower, Benjamin Stewart, Henry Tambe, Rebecca Villacorta, Raylene Young, Naphcare, Inc.; Lisa Anderson Longano, Cathi Harris, Washington State Department of Corrections; Tiffany Chan, Washington State Department of Health; Mary Huynh, CDC and Washington State Department of Health; BreAnna Brock, Whatcom County Jail, Washington; Jane Reich; staff members at the Lewis, Skagit, Spokane, Benton, Pierce, Kitsap, and Cowlitz counties and SCORE jails; Washington State Department of Corrections; Washington State Department of Health.

Corresponding author: Marc Stern, mfstern@uw.edu.

\footnotetext{
${ }^{1}$ University of Washington, Seattle; ${ }^{2}$ CDC COVID-19 Response Team; ${ }^{3}$ Washington State Department of Corrections; ${ }^{4}$ University of California, Los Angeles.
} 
All authors have completed and submitted the International Committee of Medical Journal Editors form for disclosure of potential conflicts of interest. Sharon Dolovich reports that she directs the UCLA Law COVID-19 Behind Bars Data Project, which receives grant funding from Arnold Ventures and Vital Projects Fund. No other potential conflicts of interest were disclosed.

\section{References}

1. Wallace M, Marlow M, Simonson S, et al. Public health response to COVID-19 cases in correctional and detention facilities-Louisiana, March-April 2020. MMWR Morb Mortal Wkly Rep 2020;69:594-8. PMID:32407301 https://doi.org/10.15585/mmwr.mm6919e3

2. Akiyama MJ, Spaulding AC, Rich JD. Flattening the curve for incarcerated populations-Covid-19 in jails and prisons. N Engl J Med 2020;382:2075-7. PMID:32240582 https://doi.org/10.1056/ NEJMp2005687

3. Saloner B, Parish K, Ward JA, DiLaura G, Dolovich S. COVID-19 cases and deaths in federal and state prisons. JAMA 2020;324:602-3. PMID:32639537 https://doi.org/10.1001/jama.2020.12528

4. Vicente-Alcalde N, Ruescas-Escolano E, Harboe ZB, Tuells J. Vaccination coverage among prisoners: a systematic review. Int J Environ Res Public Health 2020;17:7589. PMID:33086513 https://doi.org/10.3390/ ijerph17207589
5. Szilagyi PG, Thomas K, Shah MD, et al. National trends in the U.S. public's likelihood of getting a COVID-19 vaccine-April 1 to December 8, 2020. JAMA 2020;325:396-8. PMID:33372943 https:// doi.org/10.1001/jama.2020.26419

6. Nguyen KH, Srivastav A, Razzaghi H, et al. COVID-19 vaccination intent, perceptions, and reasons for not vaccinating among groups prioritized for early vaccination-United States, September and December 2020. MMWR Morb Mortal Wkly Rep 2021;70:217-22. PMID:33571174 https://doi.org/10.15585/mmwr.mm7006e3

7. Kaiser Family Foundation. Race, health, and COVID-19: the views and experiences of black Americans. San Francisco, CA: Kaiser Family Foundation; 2020. http://files.kff.org/attachment/Report-Race-Healthand-COVID-19-The-Views-and-Experiences-of-Black-Americans.pdf

8. Hinton EK, Henderson L, Reed C. An unjust burden: the disparate treatment of black Americans in the criminal justice system. Brooklyn, NY: Vera Institute of Justice; 2018. https:/www.vera.org/downloads/ publications/for-the-record-unjust-burden-racial-disparities.pdf

9. Ajzen I, Brown TC, Carvajal F. Explaining the discrepancy between intentions and actions: the case of hypothetical bias in contingent valuation. Pers Soc Psychol Bull 2004;30:1108-21. PMID:15359015 https://doi.org/10.1177/0146167204264079

10. Reinhart E, Chen DL. Incarceration and its disseminations: COVID-19 pandemic lessons from Chicago's Cook County Jail. Health Aff (Millwood) 2020;39:1412-8. PMID:32496864 https://doi.org/10.1377/ hlthaff.2020.00652 